\title{
A non-linear coupled fluid-structure aeroelastic analysis of a slender bridge deck
}

\author{
A. V. Lopes ${ }^{1, *, \dagger, \ddagger}$, Alvaro Cunha ${ }^{2, \S}$ and L. M. C. Simões ${ }^{1, \uparrow}$ \\ ${ }^{1}$ Faculty of Sciences and Technology of the University of Coimbra, Portugal \\ ${ }^{2}$ Faculty of Engineering of the University of Porto, Portugal
}

\begin{abstract}
SUMMARY
This paper presents a new numerical methodology for the integral aeroelastic instability analysis of slender structures, based on the appropriate conjugation of an algorithm for dynamic and geometrically non-linear analysis of structures based on the finite element method with another algorithm of computational fluid dynamics (Finite volume method). It is considered a viscous incompressible unsteady turbulent bidimensional air flow solved on a structured control volume mesh. The computer code developed on the basis of this methodology is applied to the aeroelastic study of a simply supported slender bridge deck in order to find out the critical wind velocity leading to instability. Some of the most significant results associated with the analysis of the corresponding aeroelastic behaviour are presented. Copyright (c) 2004 John Wiley \& Sons, Ltd.
\end{abstract}

KEY WORDS: aeroelastic analysis; geometric non-linear analysis; finite volume method

\section{INTRODUCTION}

Wind action is one of the most determining factors for the safety of large and flexible structures. As it is well known, since the famous Tacoma Narrows Bridge failure, in 1940, the design of long span cable-stayed and suspension bridges requires careful study of their aeroelastic behaviour under wind loads.

The characterization of aeroelastic wind action and its effects on flexible structures is a very complex task. Traditionally, this kind of work has been based on physical models tested in wind tunnels. More recently, an alternative numerical approach has been developed and refined [1-3]. This empirical theory, based on the so-called Scanlan model for the evaluation of the wind forces (aeroelastic forces), involves important simplifications. However, this nume-

\footnotetext{
* Correspondence to: A. V. Lopes, Faculty of Sciences and Technology of the University of Coimbra, Polo IIPinhal de Marrocos, 3030-290, Coimbra, Portugal.

†E-mail: avlopes@dec.uc.pt

$¥$ Assistant Professor.

$\S$ Associate Professor.

Ф Professor.
} 
rical approach requires the identification of some coefficients (drag, lift, moment coefficients and flutter derivatives) which are usually obtained from experimental studies on cross-section bridge models in wind tunnels [4-7]. Nowadays, computational models can be used to simulate external fluid flow around obstacles, so that these coefficients can be calculated by using recent developments of computational fluid dynamics (CFD) [8,9]. Anyway, these CFD tools working together with structural algorithms allow an alternative numerical approach which, depending on available computational power, should be used to perform the aeroelastic analysis [10]. By taking into account the latest developments in this field, this is the logical and improved way to follow.

In this context, the main objective of this paper is to present this new methodology for the integral aeroelastic analysis of slender structures, based on the appropriate conjugation of an algorithm of CFD (Finite volume method) with an algorithm of dynamic and geometrically non-linear analysis of structures based on the finite element method. It is considered a viscous incompressible unsteady turbulent bidimensional fluid (air) flow solved on a structured control volume mesh. The computer code developed on the basis of this new methodology is applied to the aeroelastic study of a simply supported slender bridge deck in order to find out the critical wind velocity leading to instability. The cross-section of the considered slender bridge is rectangular $(B / D=6)$.

\section{NON-LINEAR COUPLED FLUID-STRUCTURE AEROELASTIC ANALYSIS}

The computational algorithm developed to simulate aeroelastic phenomena in slender structures is a time incremental approach based on two numerical algorithms working together: one of them determines the fluid flow action and the other one evaluates the structural response. The numerical procedure used to calculate the fluid flow and its action on structures is based on the finite volume method (FVM). The finite element method is used to model the structural dynamic behaviour, which can be idealized as geometrically non-linear.

\subsection{Fluid flow simulation}

The mass-conservation, or continuity, equation and momentum-conservation equations represent the basic laws of CFD. It is assumed here that the flow is incompressible (constant density of fluid) and that the viscous stress components can be proportional to the local deformation (or strain) rates using Stokes viscosity law, i.e. the fluid is Newtonian. If turbulent flow is considered, it will also be necessary to use more equations, depending on the model used. For example, in $k-\varepsilon$ turbulence diffusion model, two more equations will be used: the turbulent kinetic energy-conservation ( $k$-equation) and the rate of viscous dissipation-conservation ( $\varepsilon$-equation) equations. Numerical procedures in CFD field use the differential form of these conservation equations, also called transport equations of a generic property $\phi$, such as each velocity component field $v_{i}$, or the turbulent kinetic energy field $k$, or the rate of viscous dissipation field $\varepsilon$. In a Cartesian domain, the general form of those differential equations can be expressed by

$$
\rho \frac{\partial \phi}{\partial t}+\rho v_{i} \frac{\partial \phi}{\partial x_{i}}=\Gamma_{\phi} \frac{\partial^{2} \phi}{\partial x_{i} \partial x_{i}}+S_{\phi}
$$


where $\rho$ represents the density of the fluid, $v_{i}$ the velocity component field at direction $i, \Gamma_{\phi}$ is the diffusion coefficient of the fluid and $S_{\phi}$ is the source term. Equation (1) has four terms: unsteady and convection terms on the left-hand side, and diffusion and source terms on the right-hand side. It is worth to point out that the convection term becomes more and more significant as the velocity field is growing.

In this case, the beginning of numerical FVM is based on the integration of these conservation equations in each control volume taken from domain discretization and on the resolution of remainder partial derivatives based on particular differentiation schemes in order to obtain some algebraic systems of equations through assembling. At each control volume, the discretized algebraic equation is set up by

$$
a_{\mathrm{P}} \phi_{\mathrm{P}}=a_{\mathrm{S}} \phi_{\mathrm{S}}+a_{\mathrm{N}} \phi_{\mathrm{N}}+a_{\mathrm{W}} \phi_{\mathrm{W}}+a_{\mathrm{E}} \phi_{\mathrm{E}}+b
$$

where $a_{i}$ is the algebraic coefficient of equation, subscript $\mathrm{P}$ denotes the central point at control volume and subscripts $\mathrm{S}, \mathrm{N}, \mathrm{W}$ and $\mathrm{E}$ denote the corresponding central points at south, north, west and east side control volumes. In Equation (2), the coefficient $a_{\mathrm{P}}$ is the amount of the remaining coefficients $a_{i}$ and $b$ represents some part of the source term. This means that, if the integrated source term $\mathrm{IS}_{\phi}$ is linearized by

$$
\mathrm{IS}_{\phi}=\mathrm{IS}_{\phi \mathrm{C}}+\mathrm{IS}_{\phi \mathrm{P}} \phi_{\mathrm{P}}
$$

then

$$
\begin{aligned}
& a_{\mathrm{P}}=a_{\mathrm{S}}+a_{\mathrm{N}}+a_{\mathrm{W}}+a_{\mathrm{E}}-\mathrm{IS}_{\phi \mathrm{P}} \\
& b=\mathrm{IS}_{\phi \mathrm{C}}
\end{aligned}
$$

After that, the boundary conditions and under-relaxation are imposed by changing some of those algebraic coefficients and all these systems of equations are solved by using particular methods. In addition, some field values are updated and/or corrected in order to get local and global conservation and to avoid values without physical meaning [11-13]. In that context, this numerical approach is stable and robust, not only via local conservation of the fluid flow's properties, but also through some rules to take into account, like consistency and transport properties.

The implemented program, based on the FVM, is suitable to simulate incompressible and isothermal bidimensional unsteady fluid flows around obstacles. It is assumed that the flow's domain may be discretized in a structured control volume mesh, whose faces have vertical and horizontal directions. The equations taken from the integration of the general transport equations in differential forms are discretized by using a hybrid differentiation scheme. In the hybrid scheme, algebraic coefficients are set up by

$$
\begin{aligned}
& a_{\mathrm{N}}=D_{n} \llbracket 0,\left(1-0,5\left|P_{n}\right|\right) \rrbracket+\llbracket-F_{n}, 0 \rrbracket \\
& a_{\mathrm{S}}=D_{s \llbracket} \llbracket 0,\left(1-0,5\left|P_{s}\right|\right) \rrbracket+\llbracket F_{s}, 0 \rrbracket \\
& a_{\mathrm{E}}=D_{e} \llbracket 0,\left(1-0,5\left|P_{e}\right|\right) \rrbracket+\llbracket-F_{e}, 0 \rrbracket \\
& a_{\mathrm{W}}=D_{w} \llbracket 0,\left(1-0,5\left|P_{w}\right|\right) \rrbracket+\llbracket F_{w}, 0 \rrbracket
\end{aligned}
$$




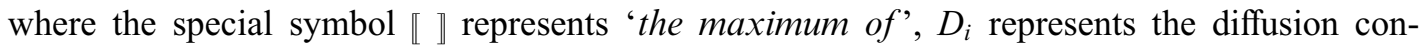
ductance on face $i, F_{i}$ the convective flux on face $i$ and $P_{i}$ is the Peclet number. To a face $i$ whose length is $\delta_{i}$, these variables are defined by

$$
D_{i}=\frac{\Gamma_{i}}{\delta_{n}} \delta_{i}, \quad F_{i}=\rho v_{i} \delta_{i}, \quad P_{i}=\frac{F_{i}}{D_{i}}
$$

where $\delta_{n}$ is the distance between the central points of control volumes that share this face.

The hybrid scheme is similar to the central-difference scheme when the convection is not important (low velocity field) and it reduces to upwind scheme when diffusion is not important (high velocity field) [11]. In fact, the central-difference scheme lacks transportiveness and gives unrealistic solutions for large values of velocity field. In order to obtain a solution on those circumstances, the transportiveness property related to directional influence of the fluid flow should be considered. On the other hand, upwind is a highly stable scheme due to conservativeness, boundness and transportiveness properties, but it suffers from false diffusion if the velocity vector is not parallel to one of the co-ordinate directions and also when there is a non-zero gradient of the dependent variable in the normal direction of the flow [13]. In order to reduce false diffusion, a refined mesh around boards of the obstacle is considered and the quadratic upstream interpolation for convective kinematics (QUICK) differentiation scheme is also used in deferred correction context [12]. QUICK is a higher-order scheme and can minimize false diffusion, but it is less computationally stable and may lead to nonphysical values. So, it should not be used as a base differentiation scheme, but as an auxiliary (and adequate) scheme. Owing to their complexity and extensity, QUICK coefficients are not indicated here, but can be found in Reference [10]. The deferred correction [12] can be used to set up the adequate (more correct) equations, but it is kept away from the computational instability at the same time. For example, when considering the flux across some face at iteration $i$, the value from adequate scheme $\left({ }_{\mathrm{A}}^{i} F\right)$ can be calculated from the flux determined by base scheme $\left({ }_{\mathrm{B}}^{i} F\right)$ plus some part of the same difference at last iteration $i-1$. This means that

$$
{ }_{\mathrm{A}}^{i} F={ }_{\mathrm{B}}^{i} F-c_{\text {dif }} *\left({ }_{\mathrm{A}}^{i-1} F-{ }_{\mathrm{B}}^{i-1} F\right)
$$

where $c_{\text {dif }}$ is a considered coefficient taking values between zero and one. Normally it is worth to consider that the difference between the adequate flux and the used flux (base value) at iteration $i$ is equal to the last iteration. So, the coefficient should have the value one in this case. The stability is preserved by the use of base scheme (hybrid) to set up all coefficients of every equation, and by taking into consideration all of the differences to adequate scheme in source term. In this context, the source term should be modified by

$$
b \rightarrow b-c_{\text {dif }}\left\lfloor\left({ }_{\mathrm{A}}^{i-1} a_{\mathrm{P}}-{ }_{\mathrm{B}}^{i-1} a_{\mathrm{P}}\right)^{i-1} \phi_{\mathrm{P}}-\sum\left({ }_{\mathrm{A}}^{i-1} a_{\text {neig }}-{ }_{\mathrm{B}}^{i-1} a_{\text {neig }}\right)^{i-1} \phi_{\text {neig }}\right\rfloor
$$

where subscript neig stands for all neighbour control volumes.

Alternate value field resulting from first derivatives of pressure (in the momentum equation) or velocity (in both momentum and continuity equations) are avoided on the basis of a staggered grid approach [11]. For each system momentum-conservation equations, this methodology moves control volumes forward, placing them between the next two points of normal mesh, instead of centring on each point (pressure nodes). So, it will be employed in a different mesh for each basic dependent variable (velocity components and pressure). This 
is the basis of the semi-implicit method for pressure-linked equations (SIMPLE) procedure $[11,13]$ also used to ensure correct linkage between pressure and velocity field values. When compared with other methodologies, SIMPLE algorithm is relatively straightforward and the determined correction pressure is satisfactory for correcting velocity fields, but not so well for correcting pressure fields. For example, SIMPLER (SIMPLE revised) algorithm shows more efficiency in calculating the pressure field [13]. All these methods are iterative algorithms and, when other scalars (like turbulent quantities) are coupled to the momentum equations, the calculation has to be done sequentially. In order to ensure stability of the iteration process of this strongly non-linear problem, all these methods require under-relaxation. For a particular iteration, under-relaxation of dependent variables is a practice where only part of the entire determined variation is assumed. It should be mentioned that the probability of instability grows as the flow velocity increases (high convective flow).

In this case, it is possible to use the same under-relaxation factors in order to get both stability and a solution procedure for transient calculations [12]. In fact, if under-relaxation is introduced by using a relation coefficient $c_{\mathrm{r}}$ and, at the same time, if a fully implicit discretization scheme is used to deal with unsteady flows, then both coefficients can be set up for each control volume by

$$
c_{\mathrm{r}}=\frac{a_{\mathrm{P}}}{a_{\mathrm{P} 0}+a_{\mathrm{P}}}
$$

and

$$
a_{\mathrm{P} 0}=\frac{\rho \mathrm{Vol}}{\Delta t}
$$

where Vol stands for the volume of control and $\Delta t$ corresponds to the time interval considered throughout incremental step. The use of the same time interval for all time increments is not required. In order to avoid instability of the process, it can be recommended that the coefficient $c_{\mathrm{r}}$ should be less than one, one would say equal to 0.5 at the most. This means that, in all control volumes domain, the coefficient $a_{\mathrm{P} 0}$ should not be less than coefficient $a_{\mathrm{P}}$. So, taking into account Equations (5), (6) and (10), the corresponding time interval for convective flows can be set up from the following inequality:

$$
\Delta t \leqslant \frac{\min \left(\delta_{n}\right)}{2 U}
$$

where $U$ represents some reference (upstream) velocity of the free flow.

In general, any flow can be characterized by a non-dimensional parameter. In particular, it is possible to use the Reynolds number defined by

$$
R e=\frac{\rho U D}{\mu}=\frac{U D}{v}
$$

where $D$ represents some reference length (for instance, frontal face height), and $\mu$ and $v$ correspond to dynamic viscosity and to cinematic viscosity. It is well known that, at low Reynolds number, the flow is considered laminar, damping out quickly occasional natural disturbances. However, most of the flows are associated with higher Reynolds number, and in this case, the flow becomes unsteady and irregular, but steady and predictable in the mean. 
The digital simulation of the fine scale random fluctuation of turbulent flow is a very difficult task. Fortunately, turbulence aspects can be decrypted by statistics $[14,15]$. Therefore, the characterization of a turbulent flow is made, in general, by the mean values of basic flow dependent variables (velocity and pressure) and by the statistical properties of their fluctuations. Then, all basic dependent variables should be decomposed into a steady mean value with a fluctuating component superimposed on it (Reynolds decomposition).

In this algorithm, the high Reynolds number $k-\varepsilon$ turbulence diffusion model is applied to simulate the flow turbulence [16-19]. By considering: (i) basic conservation equations; (ii) the Reynolds decomposition of basic flow dependent variables, (iii) derived equations and (iv) modelling of additional terms (like Reynolds stress and turbulent scalar flux), it is possible to get the time-averaged momentum-conservation equations with a similar form as Equation (1). But now, the diffusion coefficient (the so-called efficient diffusion coefficient) of these equations are stated by

$$
\Gamma_{\phi}=\Gamma+\Gamma_{\phi}^{\mathrm{t}}
$$

where $\Gamma$ represents the normal diffusion coefficient of the fluid and $\Gamma_{\phi}^{t}$ represents the turbulent diffusion coefficient, defined by

$$
\Gamma_{\phi}^{\mathrm{t}}=\frac{\mu_{\mathrm{t}}}{\sigma_{\phi}}
$$

where $\mu_{\mathrm{t}}$ is the turbulent viscosity and $\sigma_{\phi}$ is the turbulent Prandtl number of a generic property $\phi$. The turbulent viscosity is established by Prandtl-Kolmogorov formula

$$
\mu_{\mathrm{t}}=C_{\mu} \rho \frac{k^{2}}{\varepsilon}
$$

where $C_{\mu}(\approx 0.09)$ is an empirical constant obtained from experimental tests in local regions where there is similar production and dissipation of turbulent energy, and $k$ and $\varepsilon$ correspond to the turbulent kinetic energy and to the rate of viscous dissipation.

In particular, for momentum equations, the coefficient $\Gamma_{\phi}$ is called efficient viscosity coefficient expressed by $\mu_{\text {eff }}$ and is defined by

$$
\mu_{\mathrm{eff}}=\mu+\mu_{\mathrm{t}}
$$

In the same way, the pressure values in the momentum equations are also changed, as a result of the modulation, by efficient pressure $p_{\text {eff }}$ defined by

$$
p_{\text {eff }}=\bar{p}+\frac{2}{3} \rho k
$$

where the first term on the right-hand side stands for mean pressure.

This modulation is based on knowledge of $k$ and $\varepsilon$ field values, which arise from modelled terms on averaging base conservative equations. These values can be determined approximately by two different systems of equations that are set up by turbulence model: the turbulent kinetic energy-conservation ( $k$-equation) and the rate of viscous dissipation-conservation ( $\varepsilon$-equation) equations. Their forms are similar to the general form of transport differential equation (see Equation (1)). For $k$-equation, the turbulent Prandtl number of property $k\left(\sigma_{k}\right)$ is established 
equal to unity in order to define the turbulent diffusion coefficient (see Equations (13), (14)). The corresponding source term is modelled by

$$
S_{k}=P_{k}-D_{k}
$$

where the first term on the right-hand side is called the production of turbulence and the second term stands for rate of viscous dissipation. They are set up by

$$
\begin{aligned}
P_{k} & \approx \mu_{\mathrm{t}}\left(\frac{\partial \overline{v_{i}}}{\partial x_{j}}+\frac{\partial \overline{v_{j}}}{\partial x_{i}}\right) \frac{\partial \overline{v_{i}}}{\partial x_{j}} \\
D_{k} & =\rho \varepsilon
\end{aligned}
$$

For $\varepsilon$-equation, the turbulent Prandtl number of property $\varepsilon\left(\sigma_{\varepsilon}\right)$ is established equal to 1.3 in order to define the turbulent diffusion coefficient. The corresponding source term is also modelled by

$$
S_{\varepsilon}=P_{\varepsilon}-D_{\varepsilon}
$$

where the first term on the right-hand side is called the production of $\varepsilon$ and the second term stands for dissipation of $\varepsilon$. They are set up by

$$
\begin{aligned}
& P_{\varepsilon} \approx C_{1 \varepsilon} \frac{\varepsilon}{k} P_{k} \\
& D_{\varepsilon} \approx C_{2 \varepsilon} \frac{\varepsilon}{l} D_{k}=C_{2 \varepsilon} \rho \frac{\varepsilon^{2}}{k}
\end{aligned}
$$

where empirical constants are established by $C_{1 \varepsilon}=1.44$ and $C_{2 \varepsilon}=1.92$.

The model to simulate fluid flows is completed by defining boundary conditions, which can be separated into two parts: one of them for obstacle walls and the other for all limits of the considered external flow's domain (inlet and outlet). In the first case, this is done in the high Reynolds number $k-\varepsilon$ turbulence diffusion model context by defining particular values at domain nodes neighbourhood at each wall, i.e. in the turbulent boundary layer which can be separated in two others: viscous and logarithmic. However, it should be noted that these boundary conditions are valid when the first node from the wall is located in logarithmic sublayer. Problems arise in separated flows, within the recirculation region and, specially, in the separation and reattachment regions. In such cases a low Reynolds number version should be used. So, these values depend on the sub-region where every particular node is situated. In order to do that, it is required to stipulate one dimensionless distance $n^{+}$from the wall to the following particular domain node:

$$
n^{+}=\frac{\rho \delta n u_{\tau}}{\mu}
$$

where $\delta n$ is the normal distance from the node to wall and $u_{\tau}$ represents the shear velocity defined below. When taking into consideration flat plats boundary layer, a node is located in viscous sublayer if $n^{+} \leqslant 11.2$, or is collocated in logarithmic region if $n^{+}>11.2$. 
Table I. Boundary conditions at inlet and outlet regions.

\begin{tabular}{lcc}
\hline Variable & Inlet & Outlet \\
\hline Velocity $v_{i}$ & Projected fluid flow's velocity & $v_{i, \text { outlet }}=3 v_{i, \text { outlet }-1}-3 v_{i, \text { outlet }-2}+v_{i, \text { outlet }-3}$ \\
Pressure $p$ & Null & $p_{\text {outlet }}=2 * p_{\text {outlet }-1}-p_{\text {outlet }-2}$ \\
$k$ & $k_{\text {inlet }} \approx I_{\mathrm{i}}^{2} U^{2}$ & $k_{\text {outlet }}=k_{\text {outlet }-1}-\left(\frac{\varepsilon}{v_{n}}\right)_{\text {mean }} \delta x_{m}$ \\
$\varepsilon$ & $\varepsilon_{\text {inlet }} \approx \frac{I_{\mathrm{t}}^{3}}{l} U^{3}$ & $\varepsilon_{\text {outlet }}=\varepsilon_{\text {outlet }-1}-C_{2 \varepsilon}\left(\frac{\varepsilon^{2}}{k v_{n}}\right)_{\text {mean }} \delta x_{m}$ \\
\hline
\end{tabular}

If it is assumed that the node is situated in viscous sublayer, the shear velocity is determined by

$$
u_{\tau}=\sqrt{\frac{\tau_{\mathrm{w}}}{\rho}}
$$

where $\tau_{\mathrm{w}}$ is the shear stress at the wall

$$
\tau_{\mathrm{w}}=\mu \frac{v_{\mathrm{t}}}{\delta n}
$$

and $v_{\mathrm{t}}$ is the mean velocity parallel to the wall. In this case $k$ value is null, $\varepsilon$ value is set up by

$$
\varepsilon_{1 \mathrm{w}} \cong \frac{\tau_{\mathrm{w}}^{2}}{\rho \mu}
$$

and the momentum-conservation equation on direction parallel to the wall corresponding to the control volume has the contribution of shear stress (Equation (24)) throughout all shared wall.

If $n^{+}$value is bigger than the specified value, then the node is kept in logarithm sublayer and, instead of using Equation (23), the shear velocity is determined by

$$
u_{\tau} \approx C_{\mu}^{1 / 4} k^{1 / 2}
$$

In this case, $k$ value is solved by system equations and $\varepsilon$ value is set up by

$$
\varepsilon_{2 \mathrm{w}} \cong \frac{u_{\tau}^{3}}{\chi \delta n}
$$

where $\chi$ is the so-called Von Karman constant $(\chi=0.41)$. Now, the momentum-conservation equation on direction parallel to the wall corresponding to the control volume has the contribution of shear stress set up by Equations (23), (26) throughout all shared wall.

For the remaining boundary conditions in inlet and outlet regions, all variables are defined as expressed in Table I, where $U$ is the free velocity of the fluid flow, $I_{\mathrm{t}}$ and $l$ correspond to the free turbulence intensity of the fluid flow $\left(I_{\mathrm{t}} \approx 1 \%\right)$ and to the length scale of turbulence $(l \approx 0.1 \mathrm{~m}), v_{n}$ stands for the mean velocity normal to the outlet and $\delta x_{m}$ is the distance between the last two nodes. 
Furthermore, to take into account the highly non-linear character of turbulent quantity equations, it is necessary to limit the variation of $k$ and $\varepsilon$ to positive values. In order to do that, it is stated the following minimum values:

$$
\begin{aligned}
& k_{\min }=0.1 \% K_{\text {inlet }} \\
& \varepsilon_{\text {min }}=0.1 \% \varepsilon_{\text {inlet }}
\end{aligned}
$$

The iterative solution procedures for every time increment are the tri-diagonal-matrix algorithm (TDMA) line-by-line solver of the governing mass, momentum and turbulence conservation algebraic equations of viscous incompressible unsteady turbulent bidimensional fluid flow, in the SIMPLE algorithm context.

The convergence criterion for pressure-correction equations is set up by

$$
\frac{1}{n} \sum_{n} \frac{\left\|^{i} b\right\|}{\rho U} \leqslant 10^{-4}
$$

where $n$ is the number of control volumes and ${ }^{i} b$ is the source term at the $i$ th iteration.

For the remaining equations, the convergence criterion is given by

$$
\frac{1}{n} \sum_{n} \frac{\left\|\phi^{i} \phi-{ }^{i-1} \phi\right\|}{\phi_{\text {inlet }}} \leqslant 10^{-4}
$$

where ${ }^{i} \phi$ is the field of the generic property value calculated at the $i$ th iteration and $\phi_{\text {inlet }}$ is the correspondent field value in the inlet domain.

\subsection{Structural analysis}

The finite element method is used to model the structural behaviour [20-22]. The simulation of the dynamic behaviour is based on the incremental Newmark method and the corresponding integration parameters are set up according to Newmark's initial proposal (constant-averageacceleration-method). Structural damping is introduced by assuming a Rayleigh damping matrix, where the mass and stiffness matrix coefficients are evaluated by adopting two particular modal damping factors. The numerical procedures, based on an updated Lagrangian formulation, allow the consideration of global large displacements (geometrical non-linear behaviour). However, small element deformations were assumed to evaluate the structural response.

In this incremental algorithm, the main purpose at every incremental time step $\Delta t$ consists in reducing the non-balanced structural forces $\Psi$ as much as possible, which involves an iterative sub-process. When considering a time interval $[t ; t+\Delta t]$, the non-balanced forces can be set up at time $t+\Delta t$ by

$$
{ }^{t+\Delta t} \psi={ }^{t+\Delta t} q-{ }^{t+\Delta t} q_{\mathrm{ext}}
$$

where vectors $q$ and $q_{\text {ext }}$ correspond to internal and external elementary forces on all degrees of freedom. The vector $q$ is taken from assembling all elementary $e$ contributions established by

$$
{ }^{t+\Delta t} q^{e}={ }^{t+\Delta t} f_{\mathrm{int}}^{e}+{ }^{t+\Delta t} f^{e}
$$


where the vector $f_{\text {int }}$ is computed from both geometric non-linear strain matrix $\bar{B}$ and internal stress vector $\sigma$ by

$$
{ }^{t+\Delta t} f_{\text {int }}^{e}=\int_{V^{e}}\left({ }^{t+\Delta t} \bar{B}^{e}\right)^{\mathrm{T} t+\Delta t} \sigma^{e} \mathrm{~d} V
$$

where $V^{e}$ represents the elementary domain of element $e$, and the dynamic vector $f$ quantifies all external load forces on element by

$$
\begin{aligned}
{ }^{t+\Delta t} f^{e}= & { }^{t+\Delta t} f_{\mathrm{b}}^{e}+{ }^{t+\Delta t} M^{e}\left(\frac{4}{\Delta t^{2}}{ }^{t+\Delta t} \Delta a^{e}-\frac{4}{\Delta t}{ }^{t} \dot{a}^{e}-{ }^{t} \ddot{a}^{e}\right) \\
& +{ }^{t+\Delta t} C^{e}\left(\frac{2}{\Delta t}{ }^{t+\Delta t} \Delta a^{e}-{ }^{t} \dot{a}^{e}\right)
\end{aligned}
$$

where the vector $f_{\mathrm{b}}$ stands for static body forces on element, $M$ and $C$ correspond to the mass and damping matrices, and vectors $\Delta a, \dot{a}$ and $\ddot{a}$ represent the nodal displacements updating, velocities and accelerations. In this case, the mass matrix is computed by using mass consistent formulation [21].

In Equation (33), the vector $\sigma$ represents the stress vector, the geometric non-linear strain matrix $\bar{B}$ being determined by

$$
\bar{B}(a)=B_{\mathrm{L}}+B_{\mathrm{NL}}(a)
$$

in which the linear term of strain matrix $B_{\mathrm{L}}$ relates linear strain $\varepsilon_{l}$ to nodal displacements $a$ in linear form by

$$
\varepsilon_{\mathrm{L}}=B_{\mathrm{L}} \cdot a
$$

and the non-linear term of strain matrix $B_{\mathrm{NL}}$ relates non-linear term of total strain $\varepsilon_{\mathrm{NL}}$ to nodal displacements $a$ by

$$
\varepsilon_{\mathrm{NL}}=\frac{1}{2} B_{\mathrm{NL}} \cdot a
$$

In this case, total strain $\varepsilon$ is taken from

$$
\varepsilon=\varepsilon_{\mathrm{L}}+\varepsilon_{\mathrm{NL}}
$$

where $\varepsilon_{\mathrm{L}}$ and $\varepsilon_{\mathrm{NL}}$ represent the linear and non-linear parts of the strain vector, respectively.

The main objective of this dynamic and geometrically non-linear numerical algorithm is to evaluate the increment of displacements ${ }^{t+\Delta t} \Delta a$ at each time step, which will added to the displacements at the previous time instant ${ }^{t} a$ in order to obtain the updated structural shape ${ }^{t+\Delta t} a$. This goal is reached indirectly by reducing the non-balanced structural forces $\Psi$ by applying the Newton-Raphson iterative method, which can be stated by

$$
\hat{K}_{\mathrm{t}}\left({ }^{t+\Delta t} a\right)^{t+\Delta t} \Delta a+\psi\left({ }^{t+\Delta t} a\right)=0
$$

where the matrix $\hat{K}_{\mathrm{t}}$ is called stiffness efficient tangent matrix computed by

$$
\hat{K}_{\mathrm{t}}^{e}\left({ }^{t+\Delta t} a^{e}\right)=K_{\mathrm{t}}^{e}\left({ }^{t+\Delta t} a^{e}\right)+\frac{4}{\Delta t^{2}} M^{e}\left({ }^{t+\Delta t} a^{e}\right)+\frac{2}{\Delta t} C^{e}\left({ }^{t+\Delta t} a^{e}\right)
$$


In the last equation, the stiffness tangent matrix $K_{\mathrm{t}}$ in $i$ th iteration can be determined after some simplifications:

$$
K_{\mathrm{t}}^{e}\left({ }^{n} a^{e}\right)=K_{\sigma}^{e}\left({ }^{n} a^{e}\right)+K_{\mathrm{L}}^{e}+K_{\mathrm{NL}}^{e}\left({ }^{n} a^{e}\right)
$$

in which

$$
\begin{aligned}
K_{\sigma}^{e} & =\int_{V^{e}} \frac{\left(\mathrm{d} \bar{B}^{e}\right)^{\mathrm{T}}\left({ }^{n} a^{e}\right)}{\mathrm{d} a^{e}} \cdot \sigma^{e} \mathrm{~d} V \\
K_{\mathrm{L}}^{e} & =\int_{V^{e}}\left(B_{\mathrm{L}}^{e}\right)^{\mathrm{T}} \cdot D \cdot B_{\mathrm{L}}^{e} \mathrm{~d} V \\
K_{\mathrm{NL}}^{e}\left({ }^{n} a^{e}\right) & =K_{\mathrm{LNL}}^{e}\left({ }^{n} a^{e}\right)+K_{\mathrm{NLL}}^{e}\left({ }^{n} a^{e}\right)+K_{\mathrm{NLNL}}^{e}\left({ }^{n} a^{e}\right)
\end{aligned}
$$

and

$$
\begin{aligned}
K_{\mathrm{LNL}}^{e}\left({ }^{n} a^{e}\right) & =\int_{V^{e}}\left(B_{\mathrm{L}}^{e}\right)^{\mathrm{T}} \cdot D \cdot B_{\mathrm{NL}}^{e}\left({ }^{n} a^{e}\right) \mathrm{d} V \\
K_{\mathrm{NLL}}^{e}\left({ }^{n} a^{e}\right) & =\int_{V^{e}}\left[B_{\mathrm{NL}}^{e}\left({ }^{n} a^{e}\right)\right]^{\mathrm{T}} D B_{\mathrm{L}}^{e} \mathrm{~d} V \\
K_{\mathrm{NLNL}}^{e}\left({ }^{n} a^{e}\right) & =\int_{V^{e}}\left[B_{\mathrm{NL}}^{e}\left({ }^{n} a^{e}\right)\right]^{\mathrm{T}} D B_{\mathrm{NL}}^{e}\left({ }^{n} a^{e}\right) \mathrm{d} V
\end{aligned}
$$

In the last equations, matrix $D$ stands for the elasticity matrix. Owing to extend form, the progress of Equation (42) can be checked out in References [10,22], as well as all relevant formulas for the beam element.

In any incremental time interval, the convergence criterion for non-balanced forces at the $i$ th iteration is

$$
\frac{1}{n} \sum_{n} \frac{\left\|i a-{ }^{i-1} a\right\|}{L_{\mathrm{ref}}} \leqslant 10^{-6}
$$

where $n$ is the number of degrees of freedom and $L_{\text {ref }}$ is a reference length (for instance, maximum structural dimension).

\subsection{Aeroelastic algorithm}

A structural system is submitted to several forces when immersed in a fluid flow [2,23]. They depend on three fundamental effects:

- External flow instability, by velocity field fluctuations in external domain.

- Internal flow instability, by structural geometry and flow characteristics.

- Structural movements.

When the structural movements play an important role in terms of force characteristics, the corresponding forces are named self-excited. If the structure is flexible, these forces have a 
significant influence on the structural movements. The forces associated to the structure-flow interaction are called aeroelastic forces, and they depend, not only on the flow characteristics around the structural system, but also on the structural flexibility.

Therefore, the numerical algorithm used to simulate aeroelastic phenomena in an incremental form must consider the correspondence between aeroelastic forces and structural movements at every time step [10]. It should be considered that in any new time step, the values of both aeroelastic forces and structural movements are unknown. However, it is possible to use an iterative sub-process to achieve the convergence at the end of the time step. In order to do that, it should be known that: (i) the time step usually used in high Reynolds fluid flow simulations is very short when compared with the corresponding incremental structural analysis because, in such cases, the rates of flow field value changes are higher than those of movement changes; (ii) every iteration requires a lot of computational time; (iii) any right prediction about movement changes (aeroelastic forces have higher rates of changing), even a poor prediction, can greatly improve this algorithm; and (iv) in order to have a prediction, there are mechanical properties that can be considered, for example, structural inertia or, at least, structural momentum.

With the purpose of considering the structural inertia, it is possible to have a good prediction about the movements at the end of each time step, by using linear extrapolation such as

$$
{ }^{t+\Delta t} \ddot{a}_{k}=2^{t} \ddot{a}_{k}-{ }^{t+\Delta t} \ddot{a}_{k}
$$

It should be noticed that only structural transversal velocities and rotations are important to be quantified in the fluid flow simulation context. So, by using the Newmark method formulation, it is possible to obtain velocity and displacement predictions.

The iterative sub-process associated to each time increment begins based on those predictions. Then, the algorithm solves the flow equations and calculates the aeroelastic forces. Now, it is possible to determine the corresponding structural movements. If those movements are not in good agreement with the predictions, these predictions must be corrected and this sub-process should be reinitiated until convergence is achieved. The convergence criterion is similar to Equation (48).

This aeroelastic algorithm is described by the diagram presented in Figure 1.

Owing to the characteristics of bidimensional fluid flow simulation, this algorithm considers several transversal cross-sections along the slender part of the structure where the aeroelastic forces are calculated. This simplified procedure assumes that the flow is normal to the longitudinal axis of the slender structure. Moreover, the flow around one section is simulated by itself and is considered independent from the other sections.

As it is mentioned above, this aeroelastic algorithm does not consider the three-dimensional flow effects, which constitutes the weakest feature of the presented fluid-structure model. However, it is expected that the three-dimensional effects, associated to the variation of the flow and structural geometry along a third spatial dimension, are not very significant for long cable-stayed or suspension bridges. This means that there are not considerable effects coming from the flow parallel to longitudinal deck axis, and the geometry variations are only localized in a few sections, which is probably insufficient to change deeply the characteristics of the global dynamic aeroelastic forces acting on the bridge deck. Furthermore, the extension of this algorithm to three dimensional is not so easy, some improvements becoming important, namely in terms of unstructured mesh and moving meshes. Moreover, the power of the 


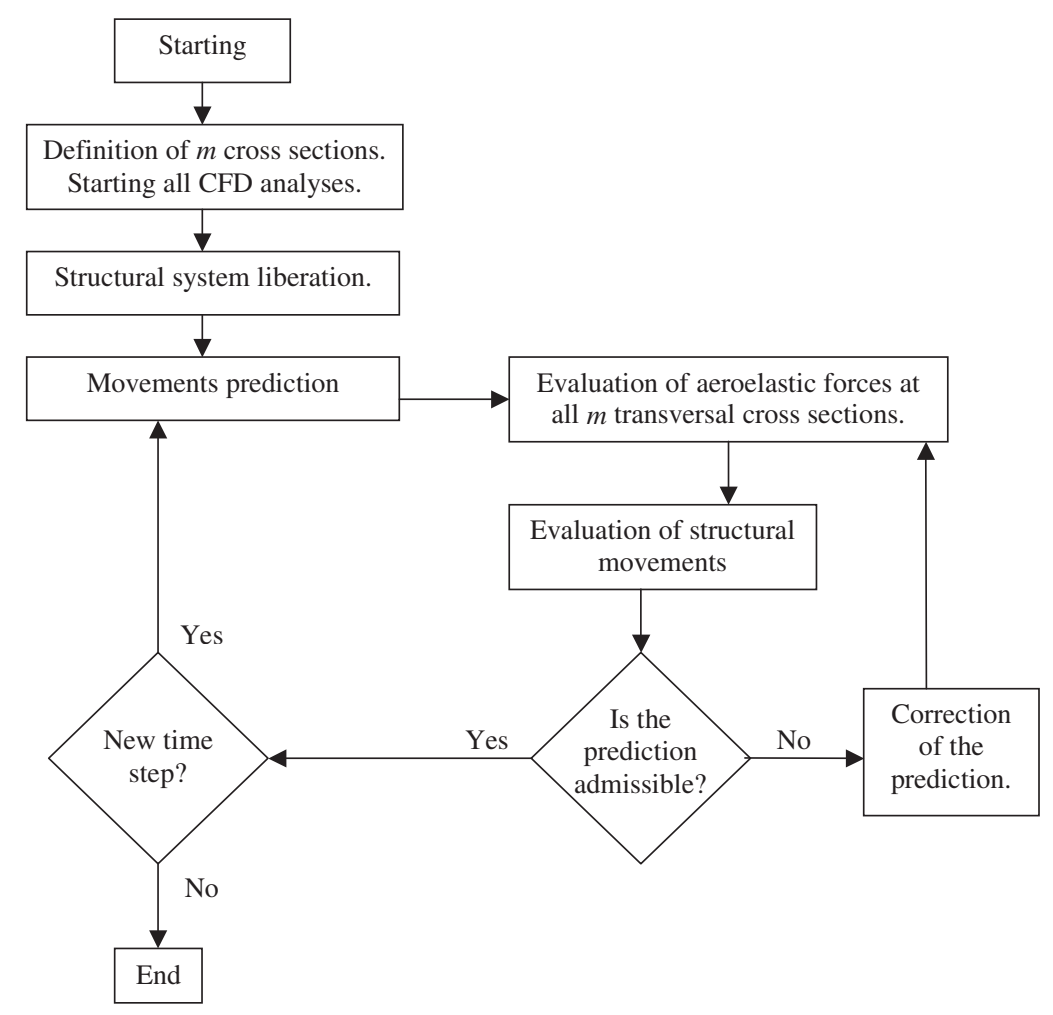

Figure 1. Aeroelastic algorithm.

present personal computers is still insufficient to deal with such complex DCF algorithms in a reasonable period of time.

\subsection{Simulation of structural movements in fluid flow}

Consider a free obstacle immerse in a bidimensional fluid flow, with the corresponding movements being characterized by displacement functions $a_{i j}$ in agreement with $O x_{i j}$-axis directions.

These movements can be modelled indirectly by changing the velocity components $\left(v_{1}\right.$ and $v_{2}$ ) of the fluid flow at external inlet boundary domain. For example, one obstacle translation $a_{i}$, in correspondence with $O x_{i}$-axis, can be modelled by specifying the velocity components of fluid flow at an inlet boundary domain through

$$
v_{j} \rightarrow v_{j}-\dot{a}_{i} \delta_{i j}
$$

where $\dot{a}_{i}$ is the velocity of the obstacle translation.

On the other hand, one obstacle rotation $a_{12}$, in correspondence with $O x_{12}$-axis, can be modelled by specifying the velocity components of fluid flow at inlet boundary domain through

$$
\left[\begin{array}{l}
v_{1} \\
v_{2}
\end{array}\right] \rightarrow T\left[\begin{array}{l}
v_{1} \\
v_{2}
\end{array}\right]
$$




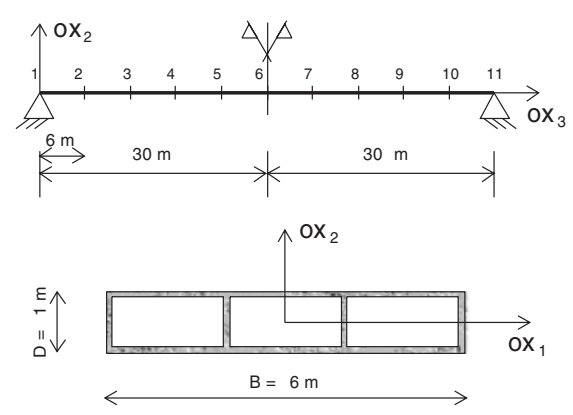

Figure 2. Geometry of simply supported slender bridge deck.

where $T$ is the transformation matrix:

$$
T=\left[\begin{array}{cc}
\cos a_{12} & \sin a_{12} \\
-\sin a_{12} & \cos a_{12}
\end{array}\right]
$$

In this previous case, the aeroelastic forces have to be determined according to $O x_{i j}$ axes, which represent general directions for structural analysis and for drag, lift and moment aeroelastic forces. This can be performed by modifying the aeroelastic forces obtained while using the transformation

$$
\left[\begin{array}{l}
F_{1} \\
F_{2}
\end{array}\right] \leftarrow T^{\mathrm{T}} \cdot\left[\begin{array}{l}
F_{1} \\
F_{2}
\end{array}\right]
$$

\section{NUMERICAL SIMULATION OF AEROELASTIC INSTABILITY}

This new methodology is applied to the aeroelastic analysis of a simply supported slender bridge deck, with rectangular cross-section (Figure 2). This structure is modelled with 10 beam elements, with the same length, whose mechanical characteristics are presented in Table II(a). Table II(b) shows the first ten natural frequencies and respective mode types. Structural damping is idealized on the basis of a Rayleigh damping matrix, whose composition is determined by assuming modal damping factors of $0.5 \%$ for the first vertical bending and torsional modes. The evaluation of the aeroelastic forces is made by simulating the fluid flow around sections 3,6 and 9. The fluid (air at standard conditions) flow mesh is built by using $96 \times 53$ control volumes (with a minimum dimension of $5 \mathrm{E}-2 \mathrm{~m}$ and a maximum of $80 \mathrm{E}-2 \mathrm{~m}$ ) as shown in Figure 3. The distances from the faces of the deck cross-section to the boundary domain are fixed so as to obtain forces not dependent upon those distances.

The simulations considered three different velocities of the free flow $(95,100$ and $105 \mathrm{~m} / \mathrm{s})$. The incremental time step used is $1.5 \mathrm{E}-3 \mathrm{~s}$ for dynamic structural analysis and, for each of these used intervals, ten incremental time steps were also adopted for fluid flow simulations. The simulation around each transversal section considers two phases: the structure is fixed in a first instance and it is free to deform in a second one. Before releasing the structure, the velocity of the free flow is elevated to the pre-defined value and the simulation is led 
Table II.

(a) Characteristics of beam elements

Axial stiffness (EA)

$O x_{1}$ flexural stiffness $\left(\mathrm{EI}_{1}\right)$

$4.5 \mathrm{E} 7 \mathrm{kN}$

$O x_{2}$ flexural stiffness $\left(\mathrm{EI}_{2}\right)$

$7.8 \mathrm{E} 6 \mathrm{kN} \mathrm{m}^{2}$

Torsional stiffness $\left(\mathrm{GI}_{p}\right)$

$1.6 \mathrm{E} 8 \mathrm{kN} \mathrm{m}^{2}$

$2.0 \mathrm{E} 6 \mathrm{kN} \mathrm{m}^{2}$

(b) Natural frequencies

\begin{tabular}{lcc} 
Mode no. & Mode type & Frequency $(\mathrm{Hz})$ \\
\hline 1 & First vertical & 0.629 \\
2 & Second vertical & 2.52 \\
3 & First lateral & 2.84 \\
4 & First torsional & 3.17 \\
5 & Third vertical & 5.67 \\
6 & Second torsional & 6.43 \\
7 & Third torsional & 9.84 \\
8 & Fourth vertical & 10.08 \\
9 & Second lateral & 11.37 \\
10 & Fourth torsional & 13.48 \\
\hline
\end{tabular}

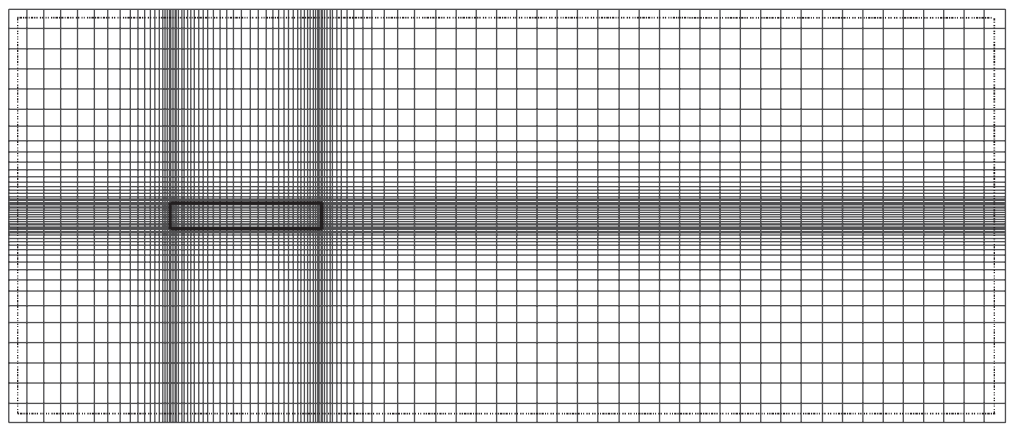

Figure 3. Control volume mesh for fluid flow simulation.

to a stable condition with small oscillatory characteristics according to each aeroelastic force. After that, the structure is liberated.

When considering the fluid flow around a fixed cross-section, at those velocities of the free flow, the mean drag coefficient is approximately of 1.15 and all oscillations of force coefficients tend to vanish. While those oscillatory characteristics are significantly in force coefficients, the predominant non-dimensional frequency (Strouhal number) is nearly 0.11 . This means that, due to geometric considerations the prominence frequency in force coefficients will be nearly $11 \mathrm{~Hz}$ for the mentioned velocities.

Tables III-V and Figures 4-29 present some more significant results concerning displacements and aeroelastic forces at the mid-span section, for different free flow velocities and certain time intervals. 'Residual' means that the value is less than the numerical precision, and 'Not regular/defined' means that the function has not a predominant oscillatory frequency value because its small chaotic characteristic is more important. 
Table III. Results at $95 \mathrm{~m} / \mathrm{s}$ flow's velocity.

\begin{tabular}{|c|c|c|c|c|c|}
\hline $\begin{array}{l}\text { Dependent } \\
\text { variable }\end{array}$ & $\begin{array}{c}\text { Time } \\
\text { interval (s) }\end{array}$ & Mean value & $\begin{array}{l}\text { Amplitude } \\
\text { value }\end{array}$ & Frequency $(\mathrm{Hz})$ & $\begin{array}{l}\text { Max. spectrum } \\
\text { value }\end{array}$ \\
\hline \multirow[t]{2}{*}{ Rotation } & $10-20$ & Residual & Residual & \multicolumn{2}{|c|}{ Not regular/defined } \\
\hline & $230-240$ & Residual & $\pm 1.0 \mathrm{e}-6 \mathrm{rad}$ & 3.07 & $3.7 \mathrm{e}-12$ \\
\hline \multirow{2}{*}{$\begin{array}{l}\text { Moment } \\
\text { coefficient }\end{array}$} & $10-20$ & Residual & $\pm 1.5 \mathrm{e}-5$ & 3.07 & $5.6 \mathrm{e}-11$ \\
\hline & $230-240$ & Residual & $\pm 1.0 \mathrm{e}-5$ & 3.07 & $1.3 \mathrm{e}-10$ \\
\hline \multirow[t]{2}{*}{ Deflection } & $10-20$ & $3.1 \mathrm{e}-5 \mathrm{~m}$ & Residual & \multirow{2}{*}{\multicolumn{2}{|c|}{$\begin{array}{l}\text { Not regular/defined } \\
\text { Not regular/defined }\end{array}$}} \\
\hline & $230-240$ & $3.2 \mathrm{e}-5 \mathrm{~m}$ & Residual & & \\
\hline \multirow{2}{*}{$\begin{array}{l}\text { Vertical force } \\
\text { coefficient }\end{array}$} & $10-20$ & Residual & Residual & \multicolumn{2}{|r|}{$3.0 \mathrm{e}-11$} \\
\hline & $230-240$ & Residual & $\pm 1.0 \mathrm{e}-5$ & 3.07 & 7.6e-11 \\
\hline \multirow{4}{*}{$\begin{array}{l}\text { Horizontal } \\
\text { displacement } \\
\text { Horizontal force } \\
\text { coefficient }\end{array}$} & $10-20$ & $6.5 \mathrm{e}-3 \mathrm{~m}$ & $\pm 1.5 \mathrm{e}-3 \mathrm{~m}$ & \multirow{2}{*}{\multicolumn{2}{|c|}{ Not regular/defined }} \\
\hline & $230-240$ & $6.5 \mathrm{e}-3 \mathrm{~m}$ & Residual & & \\
\hline & $10-20$ & 1.15 & $\pm 5.0 \mathrm{e}-4$ & 2.82 & $3.4 \mathrm{e}-6$ \\
\hline & $230-240$ & 1.15 & $\pm 1.0 \mathrm{e}-5$ & \multicolumn{2}{|c|}{ Not regular/defined } \\
\hline
\end{tabular}

Table IV. Results at $100 \mathrm{~m} / \mathrm{s}$ flow's velocity.

\begin{tabular}{|c|c|c|c|c|c|}
\hline $\begin{array}{l}\text { Dependent } \\
\text { variable }\end{array}$ & $\begin{array}{c}\text { Time } \\
\text { interval (s) }\end{array}$ & Mean value & $\begin{array}{l}\text { Amplitude } \\
\text { value }\end{array}$ & Frequency $(\mathrm{Hz})$ & $\begin{array}{l}\text { Max. spectrum } \\
\text { value }\end{array}$ \\
\hline \multirow[t]{3}{*}{ Rotation } & $10-20$ & Residual & $\pm 1.0 \mathrm{e}-6 \mathrm{rad}$ & 3.07 & $1.9 \mathrm{e}-12$ \\
\hline & $150-160$ & Residual & $\pm 3.0 \mathrm{e}-6 \mathrm{rad}$ & 3.07 & $5.1 \mathrm{e}-11$ \\
\hline & $230-240$ & Residual & $\pm 7.8 \mathrm{e}-5 \mathrm{rad}$ & 3.07 & $2.9 e-8$ \\
\hline \multirow{3}{*}{$\begin{array}{l}\text { Moment } \\
\text { coefficient }\end{array}$} & $10-20$ & Residual & $\pm 1.5 \mathrm{e}-5$ & 3.07 & $1.6 \mathrm{e}-10$ \\
\hline & $150-160$ & Residual & $\pm 3.0 \mathrm{e}-5$ & 3.07 & $2.2 \mathrm{e}-9$ \\
\hline & $230-240$ & Residual & $\pm 7.8 \mathrm{e}-4$ & 3.07 & $1.3 e-6$ \\
\hline \multirow[t]{3}{*}{ Deflection } & $10-20$ & $4.2 \mathrm{e}-5 \mathrm{~m}$ & Residual & \multicolumn{2}{|c|}{ Not regular/defined } \\
\hline & $150-160$ & $4.2 \mathrm{e}-5 \mathrm{~m}$ & Residual & 3.07 & $2.0 \mathrm{e}-12$ \\
\hline & $230-240$ & $4.0 \mathrm{e}-5 \mathrm{~m}$ & $\pm 1.7 \mathrm{e}-5 \mathrm{~m}$ & 3.07 & $1.3 \mathrm{e}-9$ \\
\hline \multirow{3}{*}{$\begin{array}{l}\text { Vertical force } \\
\text { coefficient }\end{array}$} & $10-20$ & Residual & $\pm 1.0 \mathrm{e}-5$ & 3.07 & $1.1 \mathrm{e}-10$ \\
\hline & $150-160$ & Residual & $\pm 3.0 \mathrm{e}-5$ & 3.07 & $1.5 \mathrm{e}-9$ \\
\hline & $230-240$ & Residual & $\pm 6.0 \mathrm{e}-4$ & 3.07 & $1.9 \mathrm{e}-6$ \\
\hline Horizontal & $10-20$ & $7.3 e-3 \mathrm{~m}$ & $\pm 1.5 \mathrm{e}-3 \mathrm{~m}$ & 2.82 & $1.3 e-5$ \\
\hline \multirow[t]{2}{*}{ displacement } & $150-160$ & $7.3 \mathrm{e}-3 \mathrm{~m}$ & Residual & \multirow{2}{*}{\multicolumn{2}{|c|}{ Not regular/defined }} \\
\hline & $230-240$ & $7.3 e-3 m$ & Residual & Not regular/defined & \\
\hline Horizontal force & $10-20$ & 1.15 & $\pm 7.5 \mathrm{e}-4$ & 2.82 & $3.3 e-6$ \\
\hline \multirow[t]{2}{*}{ coefficient } & $150-160$ & 1.15 & $\pm 1.0 \mathrm{e}-5$ & \multirow{2}{*}{\multicolumn{2}{|c|}{ Not regular/defined }} \\
\hline & $230-240$ & 1.15 & $\pm 1.0 \mathrm{e}-5$ & & \\
\hline
\end{tabular}

The inspection of these results permit to draw the following particular conclusions:

- After being released, the structure undergoes a small horizontal perturbation during nearly 60-70 s in a first phase. In this phase, the horizontal oscillatory frequency plays an important role. After that, this horizontal perturbation remains residual even if the instability phenomenon arises. This perturbation mainly controls the drag coefficient and it can 
Table V. Results at $105 \mathrm{~m} / \mathrm{s}$ flow's velocity.

\begin{tabular}{lccccc}
\hline $\begin{array}{l}\text { Dependent } \\
\text { variable }\end{array}$ & $\begin{array}{c}\text { Time } \\
\text { interval (s) }\end{array}$ & Mean value & $\begin{array}{c}\text { Amplitude } \\
\text { value }\end{array}$ & Frequency (Hz) & $\begin{array}{c}\text { Max. spectrum } \\
\text { value }\end{array}$ \\
\hline Rotation & $10-20$ & Residual & $\pm 2.0 \mathrm{e}-6 \mathrm{rad}$ & 3.07 & $3.1 \mathrm{e}-11$ \\
& $70-80$ & Residual & $\pm 1.1 \mathrm{e}-4 \mathrm{rad}$ & 3.07 & $6.5 \mathrm{e}-8$ \\
& $110-120$ & Residual & $\pm 1.4 \mathrm{e}-3 \mathrm{rad}$ & 3.07 & $8.9 \mathrm{e}-6$ \\
Moment & $10-20$ & Residual & $\pm 2.5 \mathrm{e}-5$ & 3.07 & $1.9 \mathrm{e}-9$ \\
coefficient & $70-80$ & Residual & $\pm 1.2 \mathrm{e}-3$ & 3.07 & $9.8 \mathrm{e}-6$ \\
& $110-120$ & Residual & $\pm 1.4 \mathrm{e}-2$ & 3.07 & \\
& & & & & $2.2 \mathrm{e}-12$ \\
Deflection & $10-20$ & $5.5 \mathrm{e}-5 \mathrm{~m}$ & Residual & 3.07 & $4.2 \mathrm{e}-9$ \\
& $70-80$ & $5.5 \mathrm{e}-5 \mathrm{~m}$ & $\pm 2.8 \mathrm{e}-5 \mathrm{~m}$ & 3.07 & $1.6 \mathrm{e}-9$ \\
& $110-120$ & $5.5 \mathrm{e}-5 \mathrm{~m}$ & $\pm 3.5 \mathrm{e}-4 \mathrm{~m}$ & 3.07 & $4.6 \mathrm{e}-6$ \\
Vertical force & $10-20$ & Residual & $\pm 2.0 \mathrm{e}-5$ & 3.07 & \\
coefficient & $70-80$ & Residual & $\pm 9.0 \mathrm{e}-4$ & 3.07 & $1.5 \mathrm{e}-5$ \\
& $110-120$ & Residual 5 & $\pm 1.1 \mathrm{e}-2$ & 3.07 & $8.6 \mathrm{e}-11$ \\
& & & & & $3.5 \mathrm{e}-6$ \\
Horizontal & $10-20$ & $8.1 \mathrm{e}-3 \mathrm{~m}$ & $\pm 1.8 \mathrm{e}-3 \mathrm{~m}$ & 2.82 & 2.82 \\
displacement & $70-80$ & $8.1 \mathrm{e}-3 \mathrm{~m}$ & $\pm 3.0 \mathrm{e}-6 \mathrm{~m}$ & Not regular/defined \\
& $110-120$ & $8.1 \mathrm{e}-3 \mathrm{~m}$ & Residual & 2.82 & Not regular/defined \\
Horizontal force & $10-20$ & 1.15 & $\pm 8.5 \mathrm{e}-4$ & Not regular/defined \\
coefficient & $70-80$ & 1.15 & $\pm 2.0 \mathrm{e}-5$ & & \\
& $110-120$ & 1.15 & $\pm 2.5 \mathrm{e}-5$ & & \\
\hline
\end{tabular}

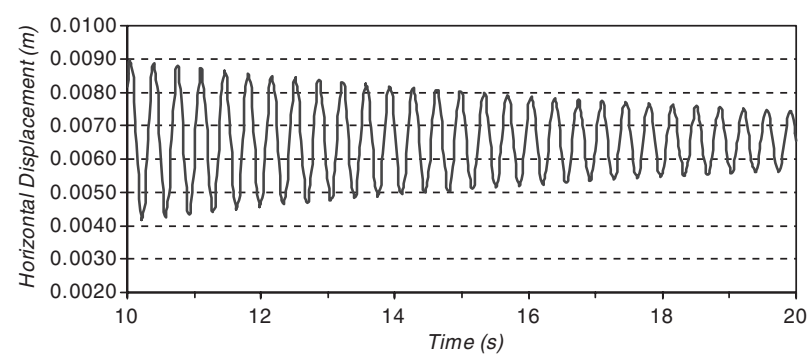

Figure 4. 10-20 s horizontal displacement at $95 \mathrm{~m} / \mathrm{s}$.

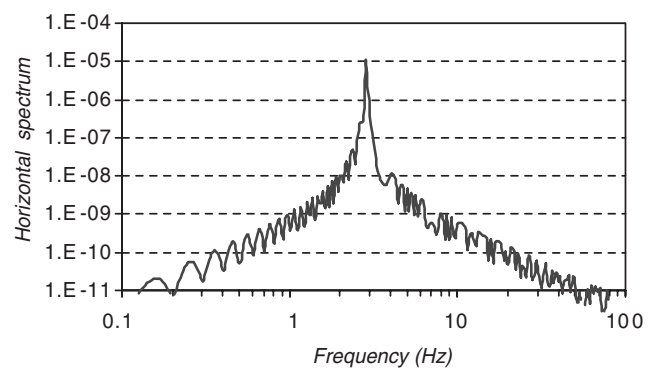

Figure 5. 10-20 s horizontal displacement spectrum at $95 \mathrm{~m} / \mathrm{s}$. 


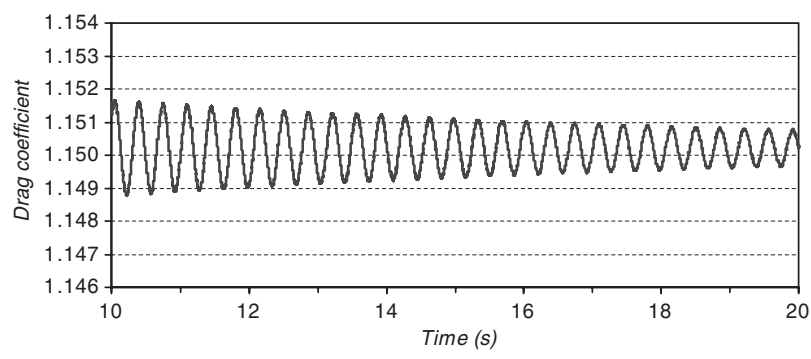

Figure $6.10-20 \mathrm{~s}$ drag coefficient at $95 \mathrm{~m} / \mathrm{s}$.

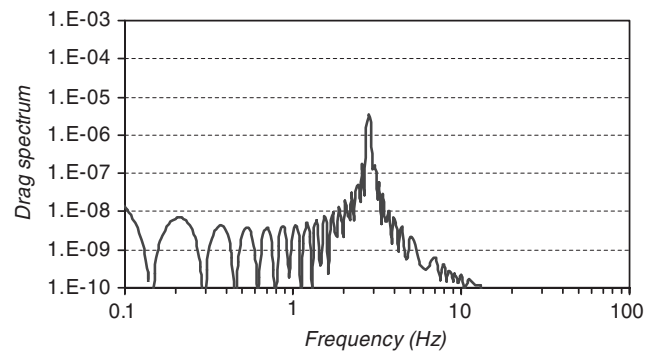

Figure 7. $10-20 \mathrm{~s}$ drag spectrum at $95 \mathrm{~m} / \mathrm{s}$.

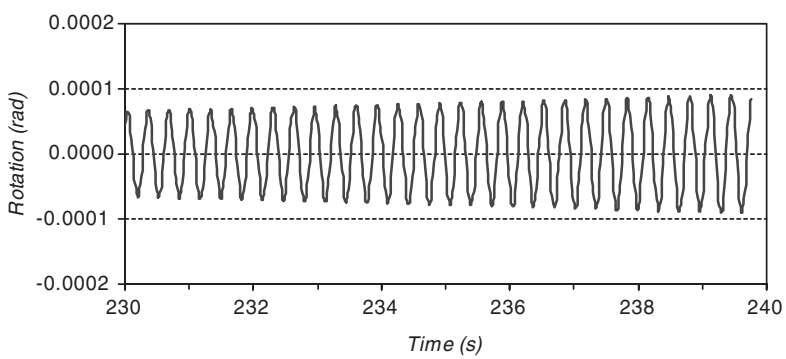

Figure $8.230-240 \mathrm{~s}$ rotation at $100 \mathrm{~m} / \mathrm{s}$.

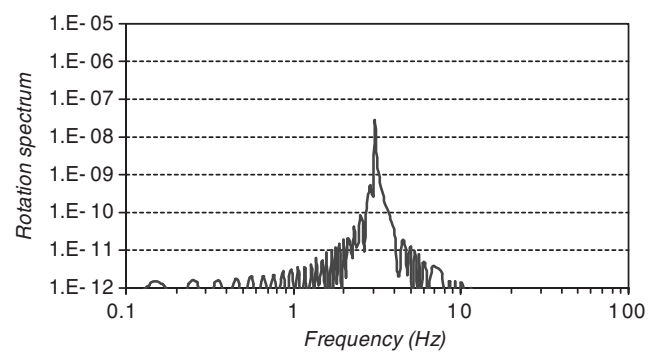

Figure 9. 230-240 s rotation spectrum at $100 \mathrm{~m} / \mathrm{s}$. 


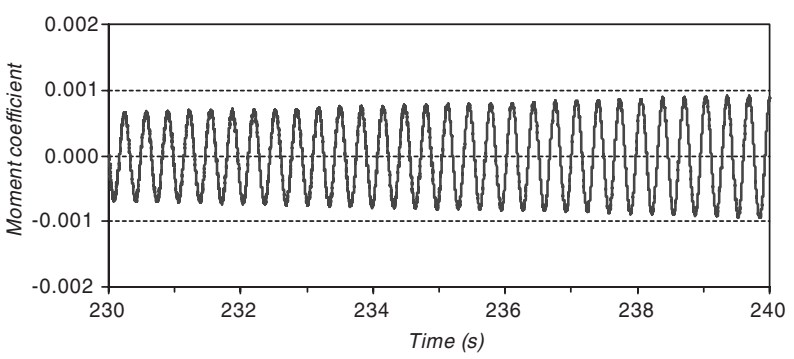

Figure 10. $230-240 \mathrm{~s}$ moment coefficient at $100 \mathrm{~m} / \mathrm{s}$.

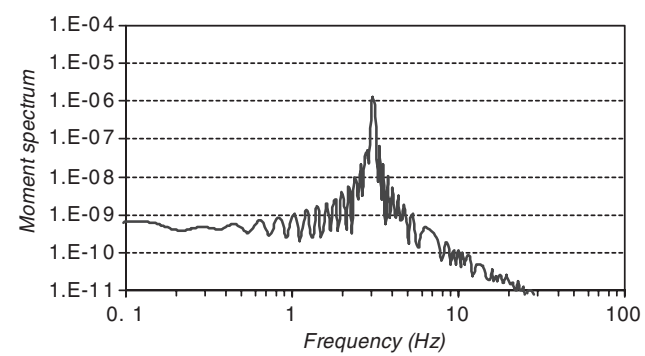

Figure 11. 230-240 s moment spectrum at $100 \mathrm{~m} / \mathrm{s}$.

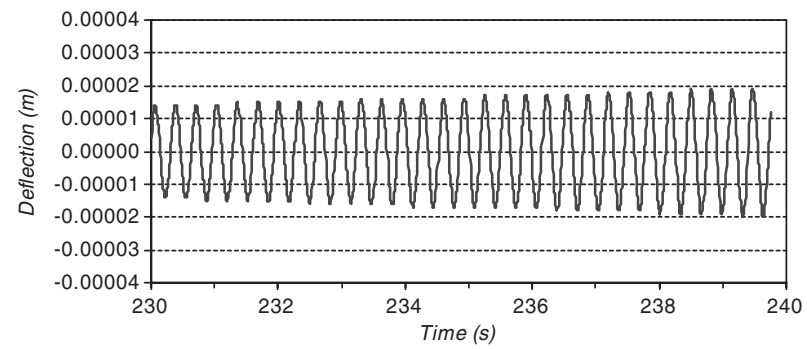

Figure 12. $230-240 \mathrm{~s}$ deflection at $100 \mathrm{~m} / \mathrm{s}$.

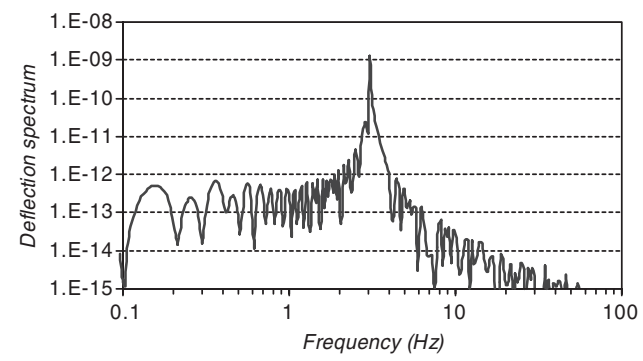

Figure 13. $230-240 \mathrm{~s}$ deflection spectrum at $100 \mathrm{~m} / \mathrm{s}$. 


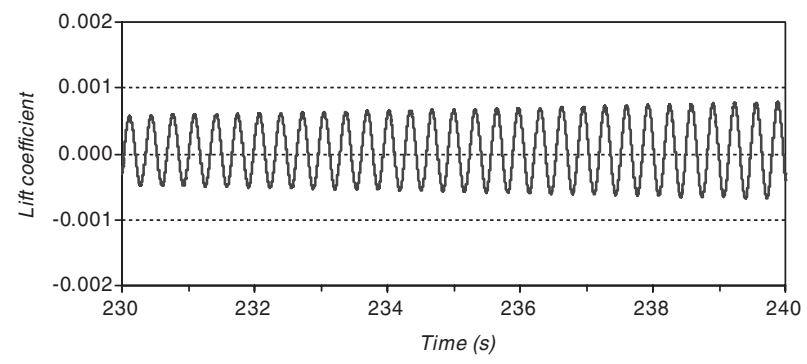

Figure 14. $230-240 \mathrm{~s}$ lift coefficient at $100 \mathrm{~m} / \mathrm{s}$.

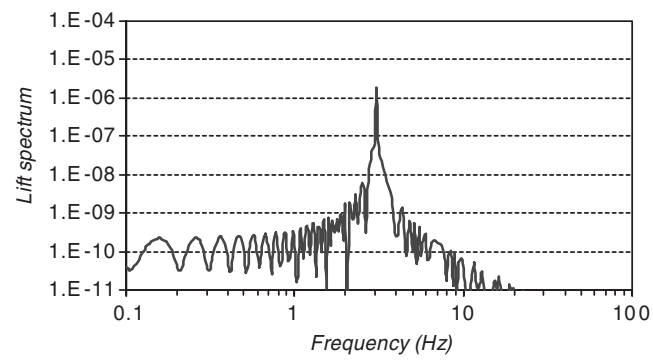

Figure 15. 230-240 s lift spectrum at $95 \mathrm{~m} / \mathrm{s}$.

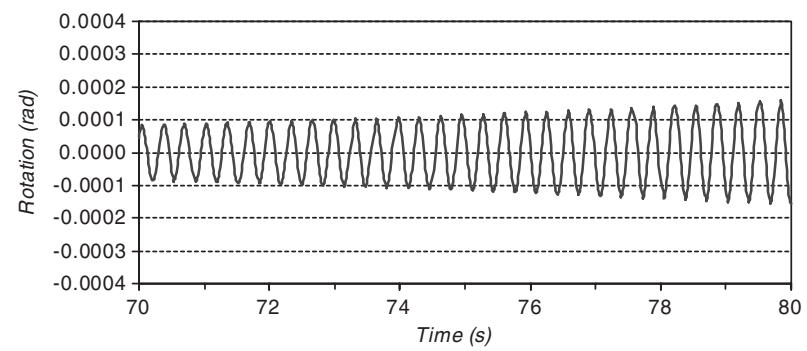

Figure $16.70-80 \mathrm{~s}$ rotation at $105 \mathrm{~m} / \mathrm{s}$.

delay the appearance of the instability phenomenon in a second phase. If it is the case, the third phase corresponds to the development of the instability phenomenon.

- The structure will not become unstable for a velocity of the free flow inferior to $95 \mathrm{~m} / \mathrm{s}$, because the amplitude of rotations, as well as the aeroelastic moments, remains almost residual after $2 \mathrm{~min}$ of simulation. Moreover, the maximum spectral values of these dependent variables do not increase in several time intervals.

- After a long time, the structure will become unstable at $100 \mathrm{~m} / \mathrm{s}$ velocity of the free flow, as the amplitude of rotations, as well as aeroelastic moments, show some incipient increase in the interval $230-240 \mathrm{~s}$ with regard to $150-160 \mathrm{~s}$.

- After a short period of time, the structure will become unstable at $105 \mathrm{~m} / \mathrm{s}$ velocity of the free flow, because it undergoes a clear increase of rotations in the time interval $110-120 \mathrm{~s}$. Beyond that, the amplitude of the aeroelastic moments increases continuously in that same period of time. 


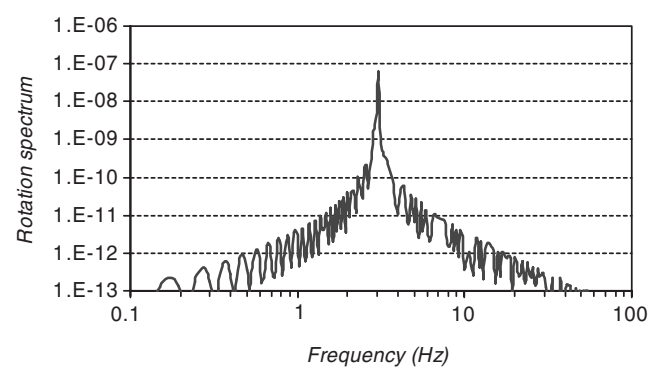

Figure 17. $70-80 \mathrm{~s}$ rotation spectrum at $105 \mathrm{~m} / \mathrm{s}$.

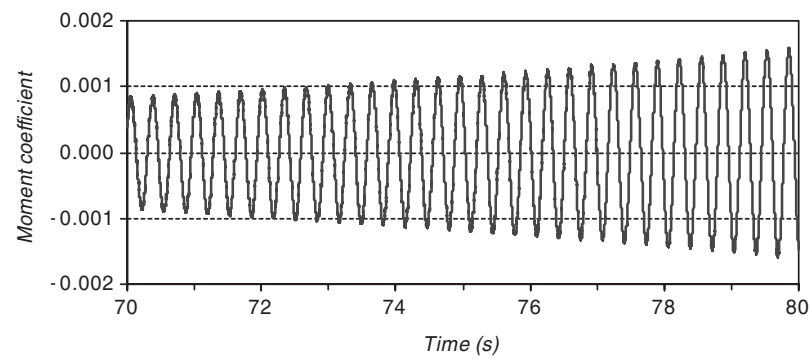

Figure 18. $70-80 \mathrm{~s}$ moment coefficient at $105 \mathrm{~m} / \mathrm{s}$.

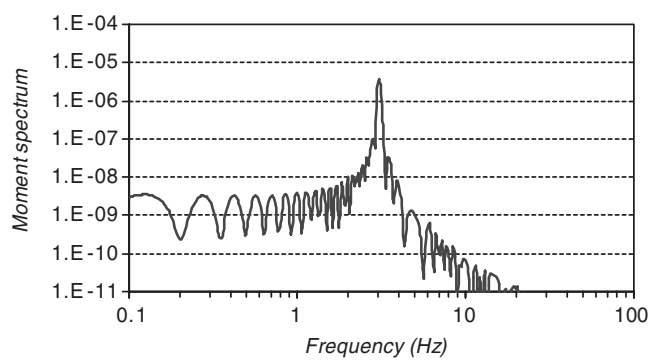

Figure 19. $70-80 \mathrm{~s}$ moment spectrum at $105 \mathrm{~m} / \mathrm{s}$.

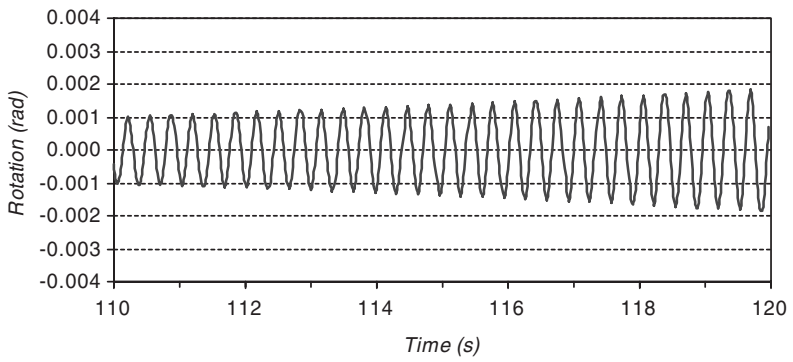

Figure $20.110-120 \mathrm{~s}$ rotation at $105 \mathrm{~m} / \mathrm{s}$. 


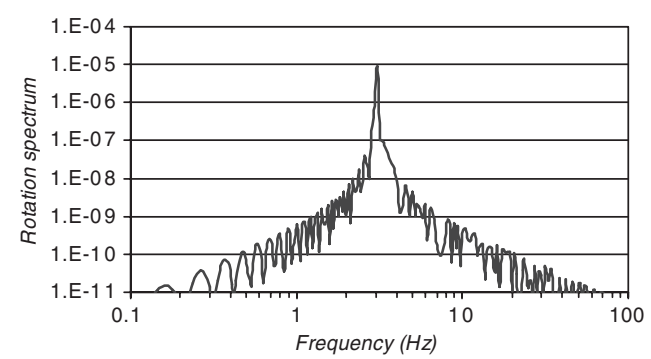

Figure $21.110-120 \mathrm{~s}$ rotation spectrum at $105 \mathrm{~m} / \mathrm{s}$.

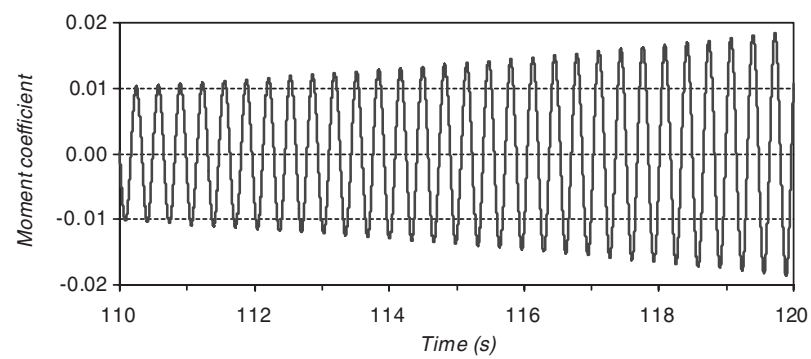

Figure 22. $110-120 \mathrm{~s}$ moment coefficient at $105 \mathrm{~m} / \mathrm{s}$.

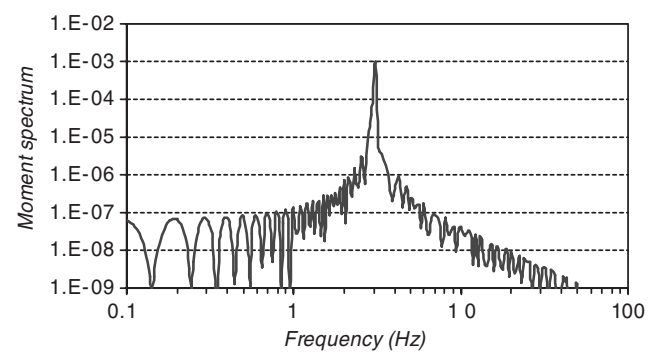

Figure 23. $110-120 \mathrm{~s}$ moment spectrum at $105 \mathrm{~m} / \mathrm{s}$.

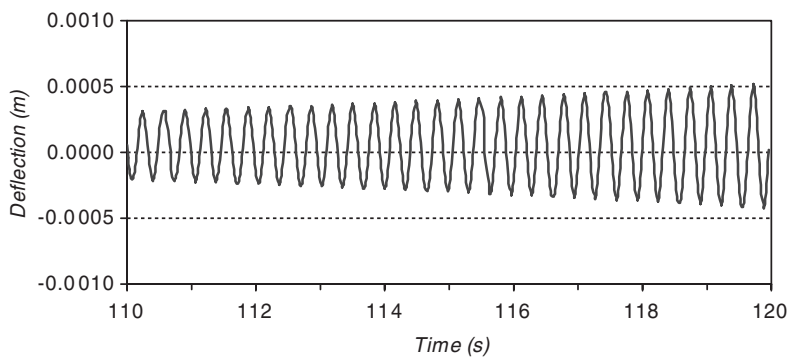

Figure 24. $110-120 \mathrm{~s}$ deflection at $105 \mathrm{~m} / \mathrm{s}$. 


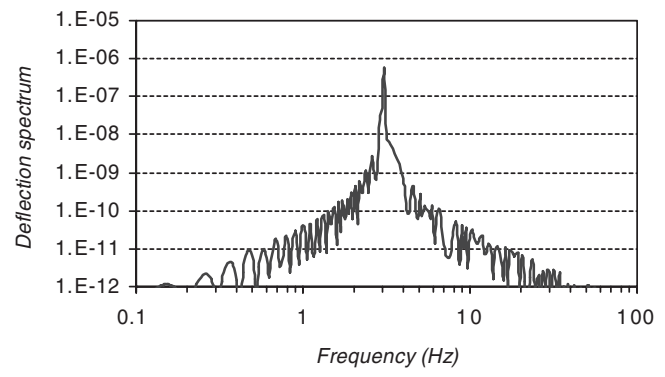

Figure 25. $110-120 \mathrm{~s}$ deflection spectrum at $105 \mathrm{~m} / \mathrm{s}$.

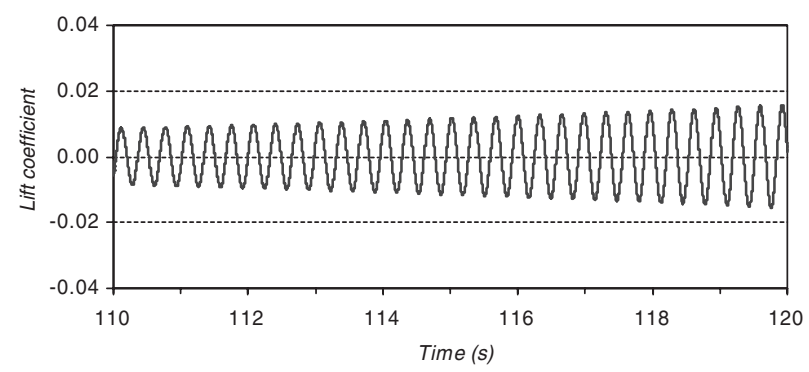

Figure 26. $110-120 \mathrm{~s}$ lift coefficient at $105 \mathrm{~m} / \mathrm{s}$.

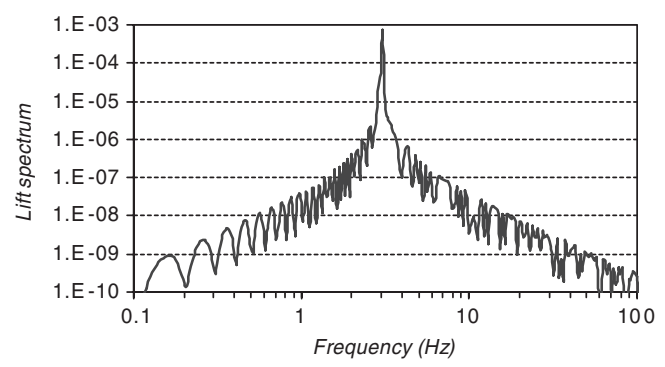

Figure 27. $110-120 \mathrm{~s}$ lift spectrum at $105 \mathrm{~m} / \mathrm{s}$.

- When it occurs, this instability phenomenon shows an oscillatory dominant frequency close to the frequency of the first torsional mode. Moreover, the amplitude of aeroelastic lifts, and after that, the amplitude of deflections grows continuously and following the instability phenomenon characteristics. But the structural vertical frequency does not play any important role.

- When compared with the second simulation, the amplitude of rotations on the third case, as well as the amplitude of aeroelastic moments increases faster.

When the instability phenomenon takes place, the amplitude of rotations on the third phase, as well as the amplitude of aeroelastic moments, shows a continuous growth as seen in 


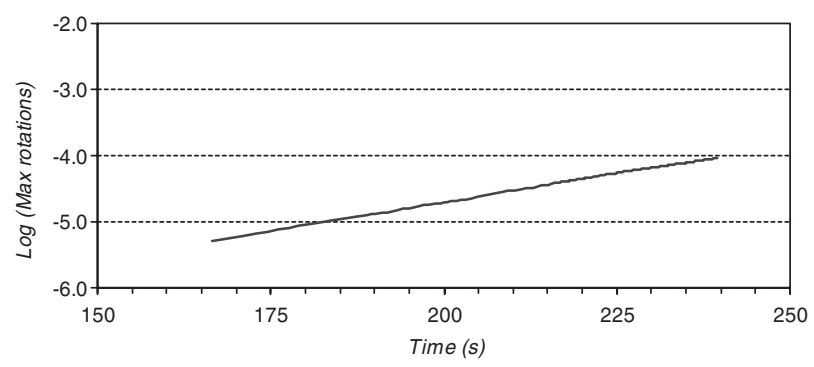

Figure 28. Maximum values of rotation at $100 \mathrm{~m} / \mathrm{s}$.

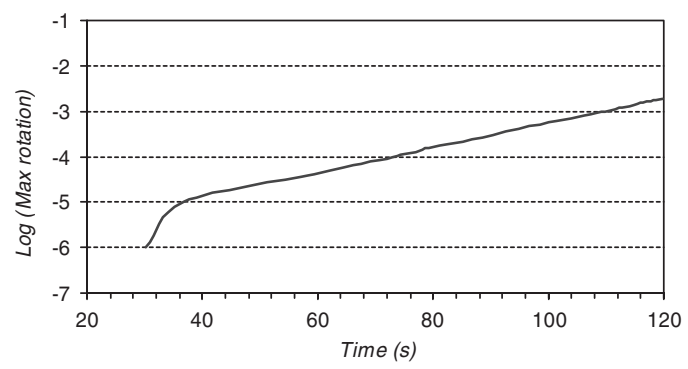

Figure 29. Maximum values of rotation at $105 \mathrm{~m} / \mathrm{s}$.

Figures 28 and 29. These graphics show the maximum values of rotations in a logarithmic scale taken during the third phase of the simulation, when the instability phenomenon is in progress. For $100 \mathrm{~m} / \mathrm{s}$ velocity of the free flow, this continuous growth arises after 150-160 s period and their logarithmic maximum rotations can be related to time by the following linear function:

$$
\log (\mathrm{rot})=0.01728 t-8.162
$$

where $t$ represents the time from the beginning of the simulation. Considering that the structural behaviour remains until self-destruction, and this will happen around 0.3 rad of rotation, then the destruction will occur at $t=7 \mathrm{~min} 21 \mathrm{~s}$. For $105 \mathrm{~m} / \mathrm{s}$ flow's velocity case, this continuous growth arises after about $40 \mathrm{~s}$ and their logarithmic maximum rotations can be related to time by the following linear function:

$$
\log (\operatorname{rot})=0.02711 t-5.975
$$

Now, if the same conditions are considered, then the destruction will occur at $t=201 \mathrm{~s}$.

So, depending on design established rules and considering the above results, the critical velocity of aeroelastic instability for this structure will be set between 95 and $105 \mathrm{~m} / \mathrm{s}$.

It is still worth noting that the last predictions about the time at which the structure is expected to reach an unsafe domain are based on a linear extrapolation of the maximum crosssection rotation, as shown in Figures 28 and 29. But, the validity of this linear assumption is certainly limited, as structural damping and stiffness will change as the structural instability 
Table VI. Critical velocity of flutter by Scanlan model.

\begin{tabular}{lcc}
\hline Fluid flow's velocity & $U_{\mathrm{r}}$ & $U_{\text {cr }}(\mathrm{m} / \mathrm{s})$ \\
\hline$R e=5 \mathrm{e} 6(U=75 \mathrm{~m} / \mathrm{s})$ & 5.8 & 110 \\
$R e=6 \mathrm{e} 6(U=90 \mathrm{~m} / \mathrm{s})$ & 6.0 & 114 \\
\hline
\end{tabular}

progresses to large deformations. Anyway, at this stage the aeroelastic forces will be able to lead this instability process to the end.

In order to find out comparison results, it is possible to get the critical velocity of flutter instability, only in torsional mode, determined by using the Scanlan model $[2,3,8,10]$. Firstly, this methodology consists in evaluating the critical Scanlan coefficient which can be done by knowing the mechanical properties of the structure. In general, Scanlan coefficients are graphically related to one non-dimensional parameter called reduced velocity. So, by knowing the critical reduced velocity $\left(U_{\mathrm{r}}\right)$, it will be possible to evaluate the corresponding critical velocity by flutter $\left(U_{\mathrm{cr}}\right)$. It is worth to mention that the last relation between Scanlan coefficients and reduced velocity is dependent on some external conditions, such as the velocity of the free flow adopted to get the mentioned graphic. In this case, the corresponding Scanlan aeroelastic coefficient determined will be $A_{2}^{*}=0.175$ if it is assumed that the effective oscillatory frequency is similar to torsional mode frequency. Table VI presents the reduced and critical flutter velocities. The reduced velocity values, related to this Scanlan coefficient, were determined by using one CDF code, two fluid flows and considering the forced oscillation method.

The Scanlan model approach provides critical flutter velocity values slightly superior to the prediction evaluated by the presented aeroelastic algorithm. As a result of different assumptions and approximations used in both approaches, such difference cannot be directly extrapolated to other examples. However, the application of the CFD approach presents the important virtue of allowing an entirely numerical assessment of this aeroelastic instability problem.

\section{CONCLUSIONS}

The results presented here illustrate a new numerical methodology for the integral aeroelastic analysis of slender structures, based on the appropriate conjugation of an algorithm of computational fluid dynamics (Finite volume method) with an algorithm for the geometrically non-linear analysis of structures.

The computer code developed on the basis of this new methodology is applied to the aeroelastic study of a simply supported slender bridge deck, with rectangular cross-section $(B / D=6)$, which enabled the characterization of possible forms of aeroelastic instability for different flow's velocities. Generally, this kind of aeroelastic phenomenon is characterized by oscillating movements and the mechanism of instability occurs when the amplitude of displacements grows consistently due to the growth of the corresponding aeroelastic forces. These forces are called self-excited because they are responsible for the growth of the amplitude of movements and, at same time, its amplitude grows along with the amplitude of movements. Usually, both forces and displacements have a particular frequency of oscillation. 
In the presented structure, characterized by a rectangular cross-section, the instability occurs in terms of rotations and the effective frequency of oscillations is similar to the fundamental frequency of torsion. Moreover, the mechanism of instability begins when the aeroelastic moments not only acquire the frequency of the torsional mode, but also have enough power to start the growth of the rotations' amplitude. After that, the rotations' amplitude growth has a particular evolution which could be represented by an expression in order to predict the achievement of a given ultimate limit state. Furthermore, aeroelastic lift forces also acquire the effective frequency of oscillations and, after that, the deflections have similar characteristics.

Although the conclusions drawn from the specific case of a simply supported slender bridge deck, with rectangular cross-section $(B / D=6)$, cannot be directly extrapolated to other situations, the methodology presented in this paper can be applied to other cases with different shapes of the deck cross-section.

It is worth mentioning that, it will be important to have specific rules in terms of characteristics of incoming fluid flow, limit state definition and maximum time period of analysis, in order to evaluate this kind of instability phenomenon. For a general structure, the critical velocity of aeroelastic instability depends on these parameters.

Further research will be now carried out in terms of more complex structures, particularly long span bridges, and the numerical results will be compared with available experimental data.

\section{REFERENCES}

1. Scanlan RH, Tomko JJ. Airfoil and bridge deck flutter derivatives. Journal of the Engineering Mechanics Division, ASCE 1971; 97(6):1717-1737.

2. Simiu E, Scanlan R. Wind effects on structures. An Introduction to Wind Engineering. Wiley: New York, 1986.

3. Jones NP, Scanlan RH. Advances (and challenges) in the prediction of long-span response to wind. Proceedings of the International Symposium on Advances in Bridge Aerodynamics: Copenhagen: Denmark. A. A. Balkema: Rotterdam, Netherlands, 1998; 59-85.

4. Nakamura Y, Mizota T. Torsional flutter of rectangular prisms. Journal of the Engineering Mechanics Division, ASCE 1975; 101(2):125-142.

5. Nakamura Y, Mizota T. Unsteady lifts and wakes of oscillating rectangular prisms. Journal of the Engineering Mechanics Division, ASCE 1975; 101(6):855-871.

6. Houston D. Flutter derivatives from 14 generic deck sections. Bridges and transmission line structures. Proceedings of the 1987 ASCE Structures Congress, Orlando, USA, 1987.

7. Shangpei L, Xin C. Experimental identification of flutter derivatives from several typical deck sections. Recent Advances in Wind Engineering. Pergamon Press: New York, 1989; 610-617.

8. Mendes, Pedro AM. Modelação Numérica do Comportamento Aerodinâmico de Estruturas Esbeltas. Ph.D. Thesis. IST: Lisboa, Portugal, 1994.

9. Walther JH. Discrete vortex method for two-dimensional flow past bodies of arbitrary shape undergoing prescribed rotary and translational motion. Ph.D. Thesis, Technical University of Denmark, Lyndby, Denmark, 1994.

10. Lopes AV. Aplicação da Dinâmica Computacional de Fluidos à Análise Aeroelástica de Estruturas Esbeltas. Ph.D. Thesis, Departamento de Eng. Civil, FCTUC, Coimbra, Portugal, 2001.

11. Patankar SV. Numerical Heat Transfer and Fluid Flow. Hemisphere Publishing Corporation: Washington, DC, 1980.

12. Ferziger JH, Peric M. Computational Methods for Fluid Dynamics. Springer: Berlin, Heidelberg, 1996.

13. Versteeg HK, Malalasekera W. An Introduction to Computational Fluid Dynamics. Longman: Malaysia, 1995.

14. Hinze JO. Turbulence (2nd edn). McGraw-Hill: New York, 1975.

15. White FM. Fluid Mechanics (2nd edn). McGraw-Hill: New York, 1986.

16. Rodi W. Turbulence Models and Their Application in Hydraulics - A State of the Art Review. International Association for Hydraulic Research: Delft, Netherlands, 1980.

17. Tennekes H, Lumley JL. A First Course in Turbulence, sixth printing. Massachusetts Institute of Technology Press: Massachusetts.

18. Hossain MS, Rodi W. A turbulence model for buoyant flows and its application to vertical buoyant jets. Turbulent Buoyant Jets and Plumes. Pergamon Press: Oxford, 1982; 121-178. 
19. Oliveira LA. Modelação Numérica de Escoamentos em Regime Turbulento. Departamento de Eng. Mecânica, Faculdade de Ciências e Tecnologia da Universidade de Coimbra, 1990.

20. Bathe K-J. Finite Element Procedures in Engineering Analysis. Prentice-Hall: New Jersey, 1982.

21. Clough RW, Penzien J. Dynamics of Structures. McGraw-Hill: New York, 1993.

22. Zienkiewicz OC, Taylor RL. The Finite Element Method (4th edn). McGraw-Hill: New York, 1989.

23. Naudascher E, Rockwell D. Flow-Induced Vibrations: An Engineering Guide. A. A. Balkema: Rotterdam, Netherlands, 1994. 